Int. J. Morphol.,

29(4):1189-1194, 2011.

\title{
Mandibular Fossa Depth Variations: Relation to Age and Dental State
}

\author{
Variaciones en la Profundidad de la Fosa Mandibular: Relaciones con Edad y Estado Dental
}

\author{
"Luis Ernesto Ballesteros Acuña; *"Luis Miguel Ramirez Aristeguieta \& *Gerardo Muñoz Mantilla
}

BALLESTEROS, L. E.; RAMIREZ, L. M. \& MUÑOZ, G. Mandibular fossa depth variations: Relation to age and dental state. Int. J. Morphol., 29(4):1189-1194, 2011.

SUMMARY: A mandibular fossa depth correlation with dental condition and age in humans. 120 fresh male mandibular fossas were measured from the deepest area of the fossa to a horizontal reference line. The samples were classified according to age and dental state (dentate, partially dentate and totally edentulous) and a multivariate analysis was employed. Subjects average age was 41.1 (20-85). There were more partially dentate individuals $(59.16 \%)$ than dentate $(30 \%)$ or edentulous ones $(10.83 \%)$. Average fossa depth was 6.9 $\mathrm{mm}(6.6-7.1 \mathrm{~mm} 95 \% \mathrm{CI})$ which significantly decreased with increased age and dental health deterioration ( $\mathrm{p}<0.01)$. A period of five years edentulism increased the likelihood of mandibular fossa flattening $(<6.9 \mathrm{~mm})$ by $20.6 \%$ and $7.2 \%$ in dentate ones. Our findings found an association between dental state and age as determinant factors in reducing mandibular fossa depth.

KEY WORDS: Temporomandibular joint; Mandibular fossa; Dental condition; Articular tubercule; Age groups.

\section{INTRODUCTION}

The temporomandibular joint (TMJ) presents a morphology in which the temporal surface constituent has an S-shape in adults sagittal configuration, consisting of a prominent articular tubercle (eminence) and a concave mandibular fossa (Nickel et al., 1988). TMJ submits intracapsular structures (condyle, disc, ligaments and mandibular fossa) to constant remodelling (adaptation) due to increased mechanical load between the TMJ's osseous structures (Moffett et al., 1964; Yamada et al., 2004). Likewise, such remodelling in the glenoid fossa and condyle that also occurs throughout life (from childhood to adult) seems to respond to a variety of conditions (Meng et al., 2008). Disuse or lesser masticatory activity in edentulous patients (having less masticatory strength) and changes in the consistency of their diets seems to generate it. Another possible cause can be observed such as partial edentulism, orthopaedic aparatology and orthodontic strengths, Angle's class II and III occlusions, overclosure, the presence of temporomandibular disorders and degenerative joint disorders, oral habits, macrotrauma and microtrauma, mandibular asymmetry, facial asymmetry and aging (Taddei et al., 1991; Jasinevicius et al., 2006a, 2006b; Floridi \& Matson, 1987; Granados, 1979; Galante et al., 1995;
Pirttiniemi et al., 1990; Katsavrias \& Halazonetis, 2005; Pirttiniemi \& Kantomaa, 1992; Touré et al., 2005; Carlsson \& Oberg, 1974; Oberg et al., 1971).

Dental erosion and total or partial edentulism seem to be correlated with flattened fossas. The absence of teeth and dental erosion are directly proportional to regressive remodelling of the articular tubercle (Carlsson \& Oberg; Blackwood, 1966). Mongini (1968, 1972) proved that regressive remodelling was present in the articular tubercle and range increased from clinical situations regarding dental erosion (due to attrition) to total edentulism. Such changes are significant when individuals have been edentulous for periods lasting more than three years (Moffett et al.).

The characteristics of the mandibular fossa have been recorded by different means: pantography, tomography, magnetic resonance, panoramic radiography, and anteroposterior and lateral radiography. Correlation has been sought between articular morphology and characteristics such as dental state, craniofacial morphology, age and gender. Attempts have been made to classify the mandibular fossa based on its vertical depth (deep, medium or flat), taking

\footnotetext{
* Titular Professor Basic Science Department, Universidad Industrial de Santander, Bucaramanga, Colombia.

${ }^{*}$ Associated Professor, Odontology Faculty, Universidad de Antioquia, Medellín, Colombia.
} 
the perpendicular to a horizontal anatomical plane as reference (Pirttiniemi \& Kantomaa; De Melo, 1973; Wedel et al., 1978; Quirch et al., 1966).

Structural variations in the TMJ related to mandibular fossa depth in cadaveric material remains a topic of interest (Tsunoda et al., 2007). This study was aimed at finding a correlation between dental state and structural remodelling of the TMJ in different aged adult males. It was expected to find a causal relationship between edentulism and regressive remodelling and reduced mandibular fossa depth.

\section{MATERIAL AND METHOD}

TMJ blocks were extracted from unclaimed fresh male cadavers (Colombian Forensic Medicine Institute) after institutional review board and University Ethics Committee's consent was obtained. A bi-auricular incision of the scalp was made during necropsy, separating the temporal-frontal and temporal-occipital flaps in anterior and posterior directions, respectively. A calvarial resection was then done via a horizontal cut through the cranium, followed by extraction of the encephalus, leaving the base of the cranium exposed. Each TMJ block was extracted using an electric saw in an approach through the middle cranial fossa. The sample obtained from each joint (together with adjacent tissue) was removed in a $6 \times 5 \times 5 \mathrm{~cm}$ block and left in $10 \%$ formaldehyde for tissue fixation and preservation. The fibers of the masetter and temporalis muscles were resected and the lateral capsule side of the TMJ was also incised. A horizontal reference line was drawn to measure the depth of the mandibular fossa, joining the maximum height of the articular tubercle and the preauricular tubercle located posterior and lateral to the squamous-tympanic fissure (Jasinevicius et al., 2006b; De Melo; Wedel et al.; Quirch et al., 1966). A perpendicular line was drawn from the deepest area of the fossa to this horizontal reference line (Fig. 1). The vertical measurement obtained represented the depth of the mandibular fossa. One researcher took this measurement with an electronic calibrator (Mitutoyo).

According to the inclusion/exclusion criteria, samples were collected from adult cadaveric males (aged over 20) that lacked any signs of trauma in the TMJ region. The samples being studied were classified according to age using the following age-ranges: $20-29,30-39,40-49,50-59$ and 60 or older. The cadaveric specimens dental state was classified as follows: dentate (having bilateral molar support and 28 or more teeth), partially dentate (lacking molar support and the presence of 6 to 20 teeth) and totally edentulous (lacking teeth) (Darling, 1984).

GLIM 4 was used for multivariate analysis, where the maximum model was simplified by the progressive elimination of conformant variables. Relative or absolute change in residual deviation caused by such removal was tested for significance using the F-ratio. A significant change was defined as that which had greater than $95 \%$ probability of not having occurred by chance.

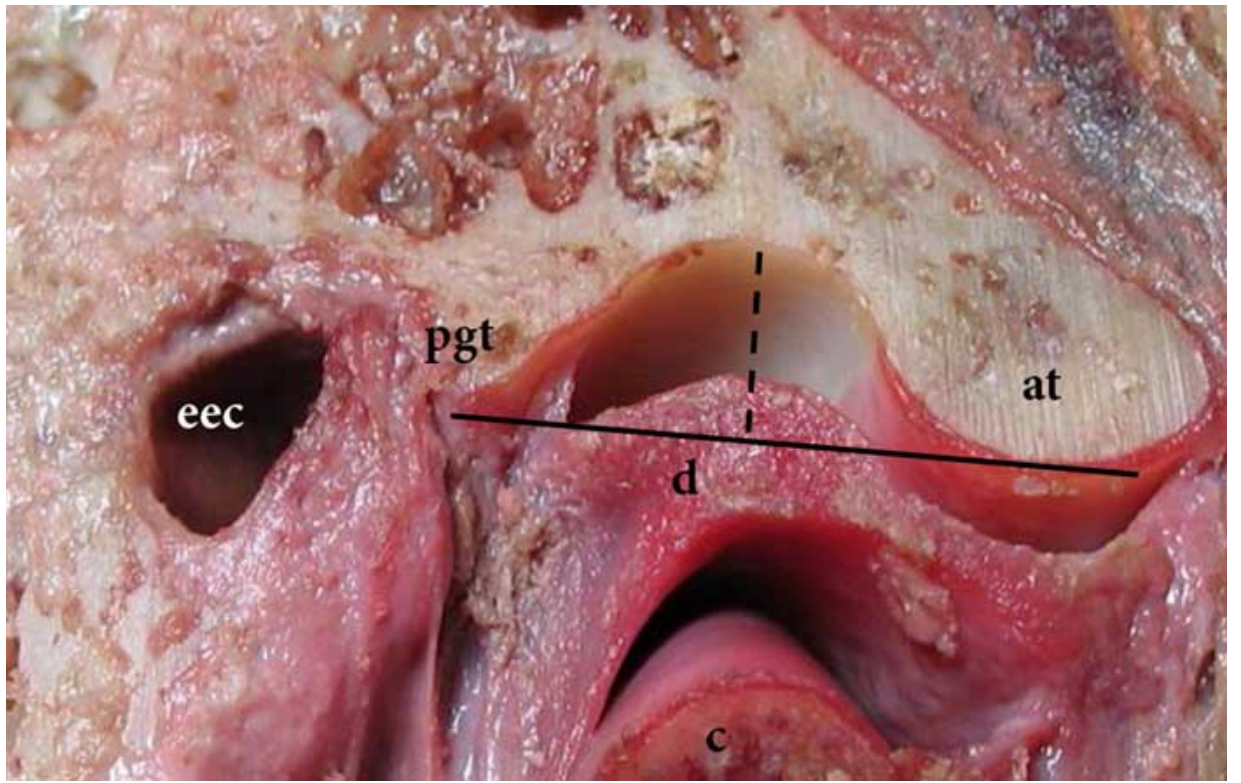

Fig. 1. Parasagittal cross-section of the right temporomandibular joint representing the measurement of mandibular fossa depth from two reference points: at: Articular tubercle, pgt: Post-glenoid crest, d: Disc, c: Condyle, eec: External ear conduct. 


\section{RESULTS}

120 blocks of TMJ were evaluated from individuals having an average age of 41 (range 20 to 85 ). The predominant dental state within the sample was partially dentate $(59.2 \%)$, followed by dentate (30\%) and edentulous $(10.8 \%)$. The dentate condition predominated during the third decade whilst partially dentate individuals were more frequent in the fourth decade and onwards until dental absence being evident in the group aged older than 60 , the edentulous condition predominating in this group (Fig. 2).

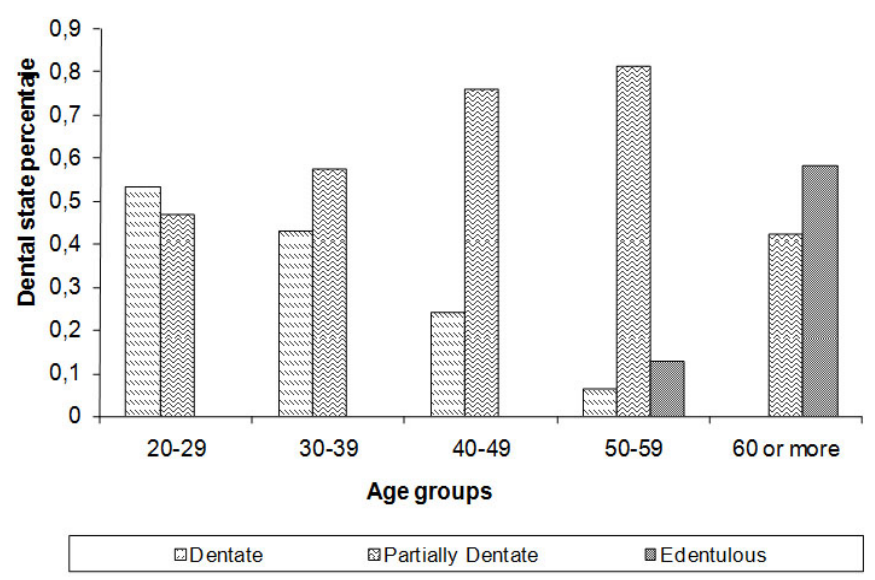

Fig. 2. The distribution of the specimens dental state by age-group. $X$ axis: age (by age group); Y axis: quality of dental state (percentage).

Average fossa depth was $6.9 \mathrm{~mm}$ (95\%CI: 6.6-7.1 mm). Greater depth was observed in the 20-29 age-group (7-31 mm), becoming significantly reduced with an increase in age (Table I). Regarding dental state, depth in the 36 dentate specimens was $7.36 \mathrm{~mm}, 6.94 \mathrm{~mm}$ in partially dentate ones (71 samples) and $6 \mathrm{~mm}$ in toothless ones (13 samples). This showed a progressive reduction in the depth of mandibular fossa related to deterioration in dental condition $(\mathrm{F}=7.7 ; 2,117$ D.F $/ \mathrm{P}<$ $0.01)$.

Table I. Mandibular fossa depth related to age.

\begin{tabular}{ccc}
\hline Age-group & Mandibular fossa block & Measurement \\
\hline $20-29$ & 32 & 7.31 \\
$30-39$ & 28 & 7.14 \\
$40-49$ & 25 & 6.96 \\
$50-59$ & 19 & 6.64 \\
$60-(+)$ & 16 & 6.12 \\
\hline
\end{tabular}

Flat fossas predominated in edentulous subjects (79.9\%) (Table II), whilst deep fossas predominated in dentate subjects $(72.3 \%)$ having significant differences (X2=11.56, 2 FG.; p<0.001). Mandibular fossa depth presented a bimodal distribution (flat and deep) having an apparent cut-off point at $6.9 \mathrm{~mm}$. Such distribution led to arbitrarily defining the dependent variable as being binary in the model. The independent variables were age (defined as continuous variable) and dental state (defined as being discrete with three factors: edentulous, partial and dentate). Univariate analysis revealed significant differences between the quality of flattening, age and dental state. Average age for specimens having flattened fossas was 46 (41.6$50.4,95 \% \mathrm{CI}$ ) whilst average age was significantly less (36.3 years) for those having deep fossas (32.9-39.6, 95\%CI). Dentate frequency was significantly higher in the group having deep mandibular fossas $(p<0.01)$.

Both variables (age and dental state) were significantly correlated with fossa depth in univariate analysis. A maximum model was created in multivariate analysis containing age, dental state and their interaction. The latter was the only variable retained in the adjusted minimum model, producing some estimates having negative intercept (c2 $=13.33$, 3 FG / p <0.01), allowing the probability of the fossa becoming flattened in differing situations to be calculated. Thus, the probability of a 55-year-old person with all his/her teeth intact of having a flattened fossa was $38.4 \%$, whilst for an edentulous person of the same age such probability increased by almost double (67.3\%). Such difference increased with age (Fig. 3). It was found that edentulism lasting five years increased the probability of mandibular fossa flattening by $20.6 \%(<6.9 \mathrm{~mm})$, whilst this was $7.2 \%$ in dentate subjects.

Table II. Distribution of dental state by type of mandibular fossa flattening.

\begin{tabular}{lcc}
\hline Dental state & Flat fossas & Deep fossas \\
\hline Dentate & $10(27.7)$ & $26(72.3)$ \\
Partially dentate & $38(53.5)$ & $33(46.5)$ \\
Edentulous & $10(79.9)$ & $3(23)$ \\
\hline Total & 58 & 62 \\
\hline \multicolumn{3}{c}{$\mathbf{\chi}=\mathbf{1 1 . 5 6}, \mathbf{2}$ FG; $\mathbf{p}<\mathbf{0 . 0 0 1}$} \\
\hline
\end{tabular}




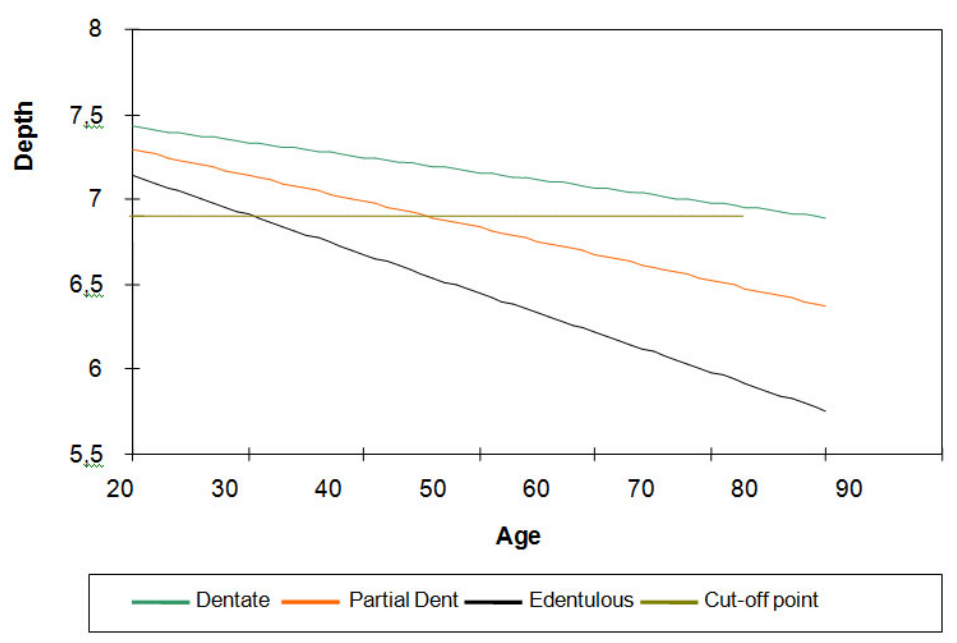

Fig. 3. Relationship between age, dental state and fossa depth.

\section{DISCUSSION}

Average depth was $6.9 \mathrm{~mm}$ in our findings, this being less than prehistoric specimens having $7.5 \mathrm{~mm}$ presented by Owen et al. (1992), Galante et al. have reported a $6.83 \mathrm{~mm}$ depth and Meng et al., show in a study with CT scanner depths of $7.17 \mathrm{~mm} \pm 1.56$. The findings of Floridi \& Matson, were $7.17 \mathrm{~mm}$ in males and $6.72 \mathrm{~mm}$ in females, no significant differences having been found between edentulous and partially edentulous subjects.

Even though De Melo reported $8.38 \mathrm{~mm}$ depths in dentate Caucasian individuals and $8.12 \mathrm{~mm}$ in toothless ones without significant differences, multivariate correlation in our findings led to significant differences being found between age-groups and dental quality. According to the results then, the probability of fossa flattening was $38.4 \%$ for an individual in whom her/his teeth had been conserved and double $(67.3 \%)$ for an edentulous condition. With this in mind, edentulism lasting for five years increased the probability $(20.6 \%)$ of mandibular fossa flattening $(<6.9 \mathrm{~mm})$, whilst this was $7.2 \%$ in dentate subjects.

There seems to be a direct proportional relationship between age and articular remodelling. Quirch et al. (1965) have shown that fossa depth becomes reduced with age. The mandibular fossa seems to become remodelled in response to changes in articular dynamics associated with biomechanical behaviour during the function and responds to forces involved in normality, dysfunctionality and disuse. Articular remodelling studies coincide regarding temporal bone, disc and condyle adaptive capacity, being greater in the latter (Yamada et al.; Hardtmann et al., 1989). According to Tourí et al. and Blackwood the mandibular fossa also becomes remodelled in response to physiological requirements originating from changes in dentition throughout life (Meng et al.). Dental state is a factor affecting articular tubercule angulation and thereby fossa depth; thus, the smaller the tubercule angle, the lesser mandibular fossa depth. Dental erosion (abrasion-attrition) and total edentulism generate flattened fossas, contrary to natural dentition or complete prosthetic state, which have shown deep fossas (Yamada et al.; Galante et al.; Jasinevicius et al., 2006b). It is understood that posterior or anterior partial edentulism generates less flattened mandibular fossas than those observed in total edentulous people who have had no restoration (Granados; De Melo).

Likewise, vertical dimension and craniocervical ratios are related to mandibular positions, which may generate two possible regressive remodelling scenarios in edentulates (Darling). Possible mechanical overload on articular tubercule and remodelling due to disuse in patients having varied muscular dynamics (due to muco-supported prosthetic situations) and in which muscular strength becomes reduced (Hardtmann et al., 1989). Reduced vertical dimension (very common in patients having a total prosthesis) generates greater dorsiflexion (ventral-extension) of the cervical column, generating protruded mandibular positions and lesser dorsal cranio-cervical angle leading to probable mechanical effects on TMJ due to an increase in condylar pressure on the temporal tubercle (Gallo, 2000).

Even though less adaptive capacity is recognized during an individual's advanced age, articular remodelling in such people has been proved to be constant, especially in edentulates having total prosthesis (Taddei et al.). The prosthetic situation of edentulates was non-existent in our samples, thereby seeming to coincide with the findings of Taddei et al. Likewise, a reduction in the height of the fossa was observed in individuals who had remained edentulous for three years compared to dentate subjects (Moffett et al.; Pirttiniemi et al.; Oberg et al.; Mongini, 1968). Seward (1976) also found a relationship between flattening of the fossa and dental erosion and loss in a study of 155 Australian aboriginal craniums. Likewise, Richards (1990) found dynamic, complex degenerative-adaptive changes in TMJ associated with the degree of dental loss, erosion and edentulism, especially in the articular condyle. Even though Wedel et al., did not coincide with these findings, they could not emphatically reject them since the population, which they had studied, was partially edentulate or had suffered recent edentulism; however, their study coincided with 
Oberg et al., on finding that $25 \%$ of the articular specimens showed flattened fossas. Hinton (1981) has stated that the morphological alteration of flattening in the TMJ responds to the degree of dental erosion or progressive edentulism and that such findings can be found between different ethnic groups (Eskimos, Australians) having different oral and dietary habits. Occlusal conditions thus seem to determine the degree of articular remodelling.

Evidently there seems to be a relationship between dental state, age and mandibular fossa depth, which was corroborated by our results. Future investigations should be focused on seeking (by anatomical or radiological methods) more evidence about the pathophysiology of these findings since it seems to have a multifactorial origin concomitant with dental state. The obtained results have clinical significance due to the correlation showed. Considering systemic disease and drug consumption individual history in clinical imagenological future studies that must be carried out that permit wider correlations.
The limitations of this study are related to the sample size, the absence of a medical systemic history and a broader classification (craniofacial, articular and dental occlusion relations) that may modify the interpretation of future results.

\section{CONCLUSION}

Our findings led to pointing out the association between dental state and age as being determinant factors in reducing mandibular fossa depth.

\section{ACKNOWLEDGEMENTS}

We would like to thank the Forensic Medicine Institute (Instituto de Medicina Legal) for its muchappreciated donation of samples.

BALLESTEROS, L. E.; RAMIREZ, L. M. \& MUÑOZ, M. G. Variaciones en la profundidad de la fosa mandibular: Relaciones con edad y estado dental. Int. J. Morphol., 29(4):1189-1194, 2011.

RESUMEN: Se observó la correlación entre la profundidad de la fosa mandibular con la condición dental y la edad en los humanos. 120 fosas mandibulares frescas de hombres fueron medidas desde la zona más profunda de la fosa a una línea horizontal de referencia. Las muestras fueron clasificadas de acuerdo a la edad y el estado dental (dentados, parcialmente dentados y desdentados en total) empleando un análisis multivariado. La edad media de los sujetos fue de 41,1 (20-85). Hubieron más personas parcialmente dentadas $(59,16 \%)$ que los dentadas $(30 \%)$ o desdentadas $(10,83 \%)$. La profundidad media de la fosa media fue de $6,9 \mathrm{~mm}(6.6 \mathrm{a} 7.1 \mathrm{~mm}$, IC 95\%) la cual disminuyó significativamente con el aumento de edad y el deterioro de la salud dental (p <0,01). Un periodo de cinco años de edentulismo aumentó de la probabilidad de aplanamiento de la fosa mandibular $(<6,9 \mathrm{~mm})$ en un $20,6 \%$ y $7,2 \%$ en los dentados. Nuestros hallazgos encontraron una asociación entre el estado dental y la edad como factores determinantes en la reducción de profundidad en la fosa mandibular.

PALABRAS CLAVE: Articulación temporomandibular; Fosa mandibular, Condición dental; Tubérculo articular; Grupos etarios.

\section{REFERENCES}

Blackwood, H. J. Adaptive changes in the mandibular joints with function. Dent. Clin. North. Am., Nov:559-66, 1966.

Carlsson, G. E. \& Oberg, T. Remodelling of the temporomandibular joints. Oral Sci. Rev., 6(0):53-86, 1974.

Darling, D. W. Relationship of head posture and the rest position of the mandible. J. Prosthet. Dent., 52(1):111-5, 1984.

De Melo, J. B. Profundidade das fossas mandibulares em cranios humanos. Rev. Fc. Odont. Sao Jose dos Campos, 2:89-96, 1973.

Floridi, A. \& Matson, E. Contribution to the study of variation of the depth of the human jaw cavity, face of the total absence of the permanent teeth. Rev. Odont. USP, 1:42-5, 1987.
Galante, G.; Paesani, D.; Tallents, R. H.; Hatala, M. A.; Katzberg, R. W. \& Murphy, W. Angle of the articular eminence in patients with temporomandibular joint dysfunction and asymptomatic volunteers. Oral Surg. Oral Med. Oral Pathol. Oral Radiol. Endod., 80(2):242-9, 1995.

Gallo, L. M. Stress-field translation in the healthy human temporomandibular joint. J. Dent. Res., 79(10):1740-6, 2000.

Granados, J. I. The influence of the loss of teeth and attrition on the articular eminence. J. Prosthet. Dent., 42(1):78-85, 1979.

Hardtmann, G.; Pröschel, P. \& Ott, R. W. Masticatory forces and maximum jaw closure forces of complete denture wearers before and after bite opening. Dtsch. Zahnarztl. Z., 44(1):26-9, 1989. 
Hinton, R. J. Changes in articular eminence morphology with dental function. Am. J. Phys. Anthropol., 54(4):439-55, 1981.

Jasinevicius, T. R.; Pyle, M. A.; Lalumandier, J. A.; Nelson, S.; Kohrs, K. J.; Türp, J. C. \& Sawyer, D. R. Asymmetry of the articular eminence in dentate and partially edentulous populations. Cranio, 24(2):85-94, 2006 a.

Jasinevicius, T. R.; Pyle, M. A.; Nelson, S.; Lalumandier, J. A.; Kohrs, K. J. \& Sawyer, D. R. Relationship of degenerative changes of the temporomandibular joint (TMJ) with the angle of eminentia. J. Oral Rehabil., 33(9):638-45, 2006 b.

Katsavrias, E. G. \& Halazonetis, D. J. Condyle and fossa shape in Class II and Class III skeletal patterns: a morphometric tomographic study. Am. J. Orthod. Dentofacial Orthop., 128(3):337-46, 2005.

Meng, F.; Liu, Y.; Hu, K.; Zhao, Y.; Kong, L. \& Zhou, S. A comparative study of the skeletal morphology of the temporomandibular joint of children and adults. J. Postgrad. Med., 54(3):191-4, 2008.

Moffett, B. C.; Johnson, L. C.; Mccabe, J. B. \& Askew, H. C. Articular remodeling in the adult human temporomandibular joint. Am. J. Anat., 115:119-41, 1964.

Mongini, F. Changes in the temporo-mandibular joint in partial edentulism. Minerva Stomatol., 17(10):850-8, 1968.

Mongini, F. Remodelling of the mandibular condyle in the adult and its relationship to the condition of the dental arches. Acta Anat. (Basel), 82(3):437-53, 1972.

Nickel, J. C.; McLachlan, K. R. \& Smith, D. M. A theoretical model of loading and eminence development of the postnatal human temporomandibular joint. J. Dent. Res., 67(6):903-10, 1988.

Oberg, T.; Carlsson, G. E. \& Fajers, C. M. The temporomandibular joint. A morphologic study on a human autopsy material. Acta Odontol. Scand., 29(3):349-84, 1971.

Owen, C. P.; Wilding, R. J. \& Adams, L. P. Dimensions of the temporal glenoid fossa and tooth wear in prehistoric human skeletons. Arch. Oral Biol., 37(1):63-7, 1992.

Pirttiniemi, P.; Kantomaa, T. \& Rönning, O. Relation of the glenoid fossa to craniofacial morphology, studied on dry human skulls. Acta Odontol. Scand., 48(6):359-64, 1990.

Pirttiniemi, P. \& Kantomaa, T. Relation of glenoid fossa morphology to mandibulofacial asymmetry, studied in dry human Lapp skulls. Acta Odontol. Scand., 50(4):235-43, 1992.

Quirch, J. S.; Carraro, J. J. \& Franchi, E. Variations in the depth of the glenoid fossa of the temporomandibular joint according to age. Rev. Asoc. Odontol. Argent., 53:71-3, 1965.
Quirch, J. S.;Carraro, J. J. \& Itotz, M. Correlation between articular eminentia and the depth of glenoid fossa. J. Periodontal Res., 1(3):227-32, 1966.

Richards, L. C. Tooth wear and temporomandibular joint change in Australian aboriginal populations. Am. J. Phys. Anthropol., 82(3):377-84, 1990.

Seward, F. S. Tooth attrition and the temporomandibular joint. Angle Orthod., 46(2):162-70, 1976.

Taddei, C.; Frank, R. M. \& Cahen, P. M. Effects of complete denture wearing on temporomandibular joints: a histomorphometric study. J. Prosthet. Dent., 65(5):692-8, 1991.

Tsunoda, A.; Sumi, T.; Shirakura, S.; Kishimoto, S. \& Akita, K. Bony eminence on the middle cranial fossa corresponding to the temporomandibular joint. Clin. Anat., 20(5):512-5, 2007.

Touré, G.; Duboucher, C. \& Vacher, C. Anatomical modifications of the temporomandibular joint during ageing. Surg. Radiol. Anat., 27(1):51-5, 2005.

Wedel, A.; Carlsson, G. E. \& Sagne, S. Temporomandibular joint morphology in a medieval skull material. Swed. Dent. J., 2(6):177-87, 1978.

Yamada, K.; Tsuruta, A.; Hanada, K. \& Hayashi, T. Morphology of the articular eminence in temporomandibular joints and condylar bone change. J. Oral Rehabil., 31(5):438-44, 2004.

\section{Dirección para correspondencia: Dr. Luis Ernesto Ballesteros Basic Science Department Universidad Industrial de Santander Calle 108 21A-13, Bucaramanga COLOMBIA}

Teléfono: 57-097-6344000 ext. 3124 Fax: 57-097-6455693

Email: Iballest56@yahoo.es

Received: 17-03-2011

Accepted: 02-08-2011 